\title{
The Effect of Whole Egg Intake on Muscle Mass: Are the Yolk and Its Nutrients Important?
}

\author{
Heitor O. Santos, ${ }^{1}$ Gederson K. Gomes, ${ }^{1}$ Brad J. Schoenfeld, ${ }^{2}$ and Erick P. de Oliveira ${ }^{1}$ \\ ${ }^{1}$ Laboratory of Nutrition, Exercise and Health (LaNES), School of Medicine, Federal University of Uberlandia (UFU), \\ Uberlandia, Minas Gerais, Brazil; '2Department of Health Sciences, CUNY Lehman College, Bronx, NY, USA
}

\begin{abstract}
Whole egg may have potential benefits for enhancing muscle mass, independent of its protein content. The yolk comprises $\sim 40 \%$ of the total protein in an egg, as well as containing several nonprotein nutrients that could possess anabolic properties (e.g., microRNAs, vitamins, minerals, lipids, phosphatidic acid and other phospholipids). Therefore, the purpose of this narrative review is to discuss the current evidence as to the possible effects of egg yolk compounds on skeletal muscle accretion beyond those of egg whites alone. The intake of whole egg seems to promote greater myofibrillar protein synthesis than egg white intake in young men. However, limited evidence shows no difference in muscle hypertrophy when comparing the consumption of whole egg versus an isonitrogenous quantity of egg white in young men performing resistance training. Although egg yolk intake seems to promote additional acute increases on myofibrillar protein synthesis, it does not seem to further enhance muscle mass when compared to egg whites when consumed as part of a high-protein dietary patterns, at least in young men. This conclusion is based on very limited evidence and more studies are needed to evaluate the effects of egg yolk (or whole eggs) intake on muscle mass not only in young men, but also in other populations such as women, older adults, and individuals with muscle wasting diseases.
\end{abstract}

Keywords: albumin, cholesterol, myofibrillar protein synthesis, egg yolk, muscle hypertrophy, lean mass

\section{Key PoINTS}

Whole egg is a potential food source

for enhancing muscle mass,

irrespective of its protein content.

Egg yolk contains several

nonprotein components that may

have anabolic properties.

Cholesterol intake from eggs may exert some influence on

testosterone levels, but its anabolic

effect seems to be minimal for promoting muscle hypertrophy.

Whole egg intake seems to promote a greater acute muscle protein

synthesis (MPS) response when compared with egg white in young men.

Limited evidence shows that whole egg intake does not promote higher muscle mass gains than white egg intake in young men.
Chicken eggs are commonly ingested by the general population at breakfast (U.S. Department of Agriculture [USDA], 2013), as well as by physically active individuals as a regular component of a high-protein diet (Faber et al., 1986). A medium egg weighs approximately $50 \mathrm{~g}$ (33 g egg white and $17 \mathrm{~g}$ yolk), of which $12.5 \%$ of its mass corresponds to protein (mainly albumin; USDA, 2019). Albumin is a high-quality protein source (Moore et al., 2009; USDA, 2019), requiring an intake of approximately $20 \mathrm{~g}$ to

de Oliveira (erick_po@yahoo.com.br) is corresponding author, (D) https://orcid.org/ 0000-0001-8989-8344.

maximally stimulate MPS in a single meal (Moore et al., 2009). The yolk comprises $\sim 40 \%$ of the total protein in an egg (USDA, 2019; van Vliet et al., 2017) as well as containing several other nonprotein nutrients with potential anabolic effects such as microRNAs, vitamins, minerals, lipids, phosphatidic acid, and other phospholipids (Baier et al., 2015; Capiati et al., 2002; Halevy \& Lerman, 1993; Joy et al., 2014; McClung et al., 2007; Weihrauch \& Son, 1983; Yasuda et al., 2014), suggesting that whole eggs may be a potential food source for enhancing muscle mass, irrespective of its protein content.

To evaluate the possible effect of yolk and its nutrients intake on muscle mass, recent studies have compared the effects of whole egg versus egg white intake on MPS (van Vliet et al., 2017) and muscle mass gain in resistance-trained individuals (Bagheri et al., 2020, 2021). Thus, the purpose of this narrative review is to discuss the current evidence as to the effects of whole egg intake on muscle mass, exploring the possible effects of egg yolk compound that may contribute to skeletal muscle accretion beyond those of egg white alone. We also aim to highlight gaps in the current literature on the topic and help to provide direction for future research.

\section{Nonprotein Nutrients of Egg Yolk}

Besides protein content (USDA, 2019; van Vliet et al., 2017), egg yolk possesses several nonprotein nutrients with possible anabolic properties including microRNAs (Baier et al., 2015), vitamins (Capiati et al., 2002; Halevy \& Lerman, 1993), minerals (McClung et al., 2007), lipids, palmitic acid (Yasuda et al., 2014), phosphatidic acid (Joy et al., 2014), choline, and phospholipids (Weihrauch \& Son, 1983). Some of these nutrients are discussed in the following sections with respect to their potential role in anabolism. 


\section{Phospholipids}

One egg yolk contains approximately $6 \mathrm{~g}$ of lipids, of which $30 \%$ ( 1.8 g) are phospholipids (USDA, 2019). The main phospholipid class found in eggs is phosphatidylcholine, which represents $\sim 72 \%$ of phospholipids (Andersen et al., 2013). Since the habitual intake of phospholipids in the typical Western diet is $2-8 \mathrm{~g}$ (Cohn et al., 2010), whole egg is an important food source for this nutrient (Blesso, 2015). Dietary phospholipids and even some modified phospholipid compounds may have anti-inflammatory effects (Bretscher et al., 2015; Feige et al., 2010; Kullenberg et al., 2012).

Whole egg intake may decrease inflammatory biomarkers. In a 12-week study evaluating individuals with metabolic syndrome, the intake of three whole eggs per day, but not egg substitute, reduced tumor necrosis factor-alpha (Ratliff et al., 2008). Another study of same duration but in overweight individuals showed that $\mathrm{C}$-reactive protein levels were reduced after intake of whole eggs (640 mg additional cholesterol/day provided by eggs) compared to placebo (no additional dietary cholesterol), in which both groups underwent a carbohydrate-restricted diet (Blesso et al., 2013). However, this anti-inflammatory effect does not seem to occur in all populations, such as healthy individuals (Andersen, 2015). Considering that elevated $\mathrm{C}$-reactive protein and tumor necrosis factor-alpha are associated with muscle mass loss (Schaap et al., 2006, 2009), it can be hypothesized that the intake of phospholipids through whole eggs could be a protective factor for muscle maintenance in some populations, such as older adults and individuals with muscle wasting diseases. However, this rationale remains speculative, given an absence of research evaluating the isolated effects of dietary phospholipids on muscle mass.

Egg yolk contains phosphatidic acid, a phospholipid that has been investigated for its potential to increase a mammalian target of rapamycin signaling, MPS, and muscle mass (Andre et al., 2016; Gonzalez et al., 2017; Joy et al., 2014; Shad et al., 2015; Smeuninx et al., 2019). One study showed increases in a mammalian target of rapamycin signaling and muscle hypertrophy from phosphatidic acid supplementation (Joy et al., 2014), while other studies found no effects on muscle mass gain (Andre et al., 2016; Gonzalez et al., 2017). There also is evidence that phosphatidic acid supplementation can attenuate the increase in MPS induced by resistance exercise in older men (Smeuninx et al., 2019). Most studies tested the effect of soy-derived phosphatidic acid, which seems to induce a greater mammalian target of rapamycin activation than eggderived phosphatidic acid observed in vitro (Joy et al., 2014). Therefore, the effects of phosphatidic acid supplementation on muscle mass are conflicting and it remains unknown whether the phosphatidic acid consumed through egg yolk may have beneficial effects on muscle hypertrophy.

\section{Omega-3 Fatty Acids}

Omega-3 is a class of polyunsaturated fatty acids with possible effects on muscle mass (Rossato, Schoenfeld, et al., 2020). Omega3 may enhance the membrane fluidity of muscle fibers, improving the uptake of amino acids and, consequently, making the cell more sensitive to MPS (McGlory et al., 2016; Smith et al., 2011a, 2011b; Tachtsis et al., 2018). In addition, omega-3 possesses anti-inflammatory effects (McGlory et al., 2019), which can result in positive effects on muscle mass given that increased inflammation is an established cause of muscle loss (Breen \& Phillips, 2011; Roubenoff, 2007; Schaap et al., 2006, 2009).

It is well known that fish oil is the major dietary source of eicosapentaenoic acid (EPA) and docosahexaenoic acid (DHA;
USDA, 2016); however, whole egg also contains omega-3 derivatives (USDA, 2019). Overall, one yolk contains approximately $0.002 \mathrm{~g}$ of EPA and $0.019 \mathrm{~g}$ of DHA (USDA, 2019), which can vary depending on how the hens are housed (outdoors on pasture or indoors; Kuhn et al., 2014), as well as by the methods to quantify omega-3 in eggs (e.g., hydrophilic interaction liquid chromatography and gas chromatography mass spectrometry; Walczak et al., 2016). The National Health and Nutrition Examination Survey data show that both young and older adults ingest low amounts of EPA and DHA in the United States (Papanikolaou et al., 2014; Rossato, de Branco, et al., 2020). The average intake of EPA and DHA from foods by adults is $\sim 0.023$ and $\sim 0.063 \mathrm{~g} /$ day, respectively (Papanikolaou et al., 2014), while older adults consume $\sim 0.042$ and $\sim 0.077 \mathrm{~g} /$ day, respectively (Rossato, de Branco, et al., 2020). To consume this amount of DHA exclusively from whole eggs, a person would need to consume $\sim$ four eggs, whereas $\sim 21$ eggs are needed to achieve the amount of EPA. Thus, whole eggs do not seem to be a nutritionally relevant source of EPA and DHA in the American diet. In addition, it should be noted that $0.25 \mathrm{~g} /$ day of EPA/DHA are recommended by the Food and Agriculture Organization/World Health Organization Expert Consultation (Joint, 2010) and European Food Safety Authority for general health (EFSA Panel on Dietetic Products, Nutrition, \& Allergies, 2010); a daily consumption of $\sim 12$ whole eggs would be required to reach this level.

Several interventional studies evaluated the effect of high doses of EPA and DHA supplementation (most using fish oil) on muscle mass in young and older individuals (Cornish et al., 2018; Da Boit et al., 2017; Harden et al., 2014; Logan \& Spriet, 2015; Noreen et al., 2010; Robinson et al., 2008; Smith et al., 2015; Strandberg et al., 2015). Even using doses much larger than those contained in whole eggs, there is conflicting evidence as to whether EPA and DHA intakes have a beneficial effect on muscle mass (Rossato, Schoenfeld, et al., 2020). Therefore, it is unlikely that the EPA and DHA contained in yolk have important effects on regulating muscle mass.

\section{Cholesterol}

The yolk of a medium egg contains $\sim 225 \mathrm{mg}$ of cholesterol (McCance \& Widdowson, 2004), which conceivably could have indirect anabolic effects, since testosterone is synthesized from cholesterol (Johnson \& Wood, 2001). Testosterone is an anabolic hormone that plays an essential role in the maintenance of muscle mass and strength (Herbst \& Bhasin, 2004), and many consumer websites claim that ingesting whole eggs, and consequently cholesterol, is a viable strategy to increase testosterone levels; however, these claims lack a sound scientific basis.

To date, only one study has evaluated the effect of high dietary cholesterol intake mainly through whole eggs on testosterone levels. Bagheri et al. (2021) compared the intake of three whole eggs $(842 \mathrm{mg} /$ day of cholesterol, being $672 \mathrm{mg}$ exclusively from eggs) versus six egg whites ( $285 \mathrm{mg} /$ day of cholesterol, being $0 \mathrm{mg}$ from eggs) on testosterone levels in young adults who performed 12 weeks of resistance training. The whole egg group increased testosterone levels by $2.4 \mathrm{ng} / \mathrm{ml}$, while the egg white group increased levels by $0.7 \mathrm{ng} / \mathrm{ml}$; however, the additional increase in testosterone levels induced by whole eggs intake was not sufficient to enhance gains in muscle mass (Bagheri et al., 2021). It is conceivable that testosterone fluctuations within the established normal physiological range for men (i.e., 300-800 ng/dl) does not have a meaningful impact on human anabolism (Morton et al., 2016; West et al., 2009), although some evidence challenges this 
hypothesis (Mouser et al., 2016). In sum, the limited evidence shows that consumption of cholesterol from eggs may exert some influence on testosterone levels, but its anabolic effect seems ineffectual for promoting exercise-induced muscle hypertrophy. More studies are needed evaluating the effects of a greater amount (greater than three eggs) of whole eggs on testosterone levels.

\section{Vitamin D}

Egg yolk contains vitamin D (USDA, 2019), which has been positively associated with muscle mass (Tieland et al., 2013). Besides their natural vitamin $\mathrm{D}$ content, eggs can be fortified with $\mathrm{D}_{3}$ and $25(\mathrm{OH}) \mathrm{D}_{3}$ to avoid vitamin $\mathrm{D}$ deficiency (Guo et al., 2018). Eggs can naturally be fortified with vitamin D by three methods: feeding more vitamin $\mathrm{D}_{3} / 25(\mathrm{OH}) \mathrm{D}_{3}$ to the hens, exposing the hens to ultraviolet $\mathrm{B}$ (UVB), and exposing liquid egg products to UVB (Barnkob et al., 2020). Interestingly, in an 8-week randomized clinical trial conducted in winter, restricted egg intake ( $\leq 2 \mathrm{eggs} /$ week) resulted in $\sim 6-7 \mathrm{nmol} / \mathrm{L}$ lower serum $25(\mathrm{OH}) \mathrm{D}$, while seven vitamin $\mathrm{D}_{3}$-enhanced eggs/week or seven $25(\mathrm{OH}) \mathrm{D}_{3}$ enhanced eggs/week maintained the preintervention $25(\mathrm{OH}) \mathrm{D}$ levels (Hayes et al., 2016). These results show that vitamin Denhanced eggs can be a viable strategy to maintain $25(\mathrm{OH}) \mathrm{D}$ levels.

A meta-analysis showed that vitamin D supplementation (300-4,000 IU/day) has a small positive effect on muscle strength (mainly in individuals presenting chronically low vitamin D levels and in older adults), but no effects were shown for muscle mass (Beaudart et al., 2014). Thus, considering that high doses of vitamin D intake have no effect on augmenting hypertrophy, it is unlikely that the vitamin D contained in egg yolk would have a meaningful beneficial effect on muscle mass, since each (nonvitamin D fortified) egg contains only 37 IU of vitamin D (USDA, 2019). Importantly, the vitamin D content in eggs can vary dramatically (fourfold) based on how the hens are housed (outdoors on pasture or indoors; Kuhn et al., 2014). Therefore, from a practical standpoint, it would be necessary to ingest $\sim 8-100$ whole eggs per day to achieve the amount of vitamin D assessed in the meta-analysis (Beaudart et al., 2014), which is not a viable nutritional strategy.

\section{Whole Egg Versus Egg White on MPS}

Considering that yolk contains nonprotein nutrients with potential anabolic properties (Baier et al., 2015; Capiati et al., 2002; Halevy \& Lerman, 1993; Joy et al., 2014; McClung et al., 2007; Weihrauch \& Son, 1983; Yasuda et al., 2014), van Vliet et al. compared the effects of whole egg (18 $\mathrm{g}$ protein and $17 \mathrm{~g}$ fat) versus egg white (18 $\mathrm{g}$ protein and $0 \mathrm{~g}$ fat) intakes on MPS after a resistance training session in healthy young men (van Vliet et al., 2017). The ingestion of whole eggs resulted in a greater stimulation of acute MPS when compared with egg whites (van Vliet et al., 2017; Figure 1a). This comparison is particularly interesting since it affords the ability to evaluate the isolated effects of nonprotein yolk nutrients on MPS. Another possible explanation for a higher MPS after whole egg intake is the increased energy content when compared with egg whites. It is known that increased energy is important to nitrogen balance when exercise is performed (Todd et al., 1984); thus, the greater energy content in whole eggs may also have contributed for a greater MPS. A similar result was observed comparing whole milk versus fat-free milk intakes, in which the greater energy in whole milk may have increased the net amino acid uptake for threonine (Elliot, Cree, Sanford, Wolfe, \& Tipton, 2006). It is also important to note that in the van Vliet et al. study a suboptimal dose of protein was administered, since participants ingested $18 \mathrm{~g}$ of protein at a mean body weight equal to $88 \mathrm{~kg}$ (van Vliet et al., 2017). This corresponds to a consumption of $\sim 0.20 \mathrm{~g} / \mathrm{kg}$ per meal, whereas a dose of $0.25-0.30 \mathrm{~g} / \mathrm{kg}$ of protein per meal is generally recommended to maximize the MPS response to resistance training (Moore et al., 2015). Therefore, the limited data to date suggests that yolk intake may provide additional increases in MPS when suboptimal doses of protein are ingested, but it remains undetermined whether these effects would persist with ingestion of adequate doses of protein $(\sim 0.30 \mathrm{~g} / \mathrm{kg}$ per meal). Thus, future studies should compare the effects of whole egg versus egg whites on MPS with provision of higher doses of protein. (a) Acute effect

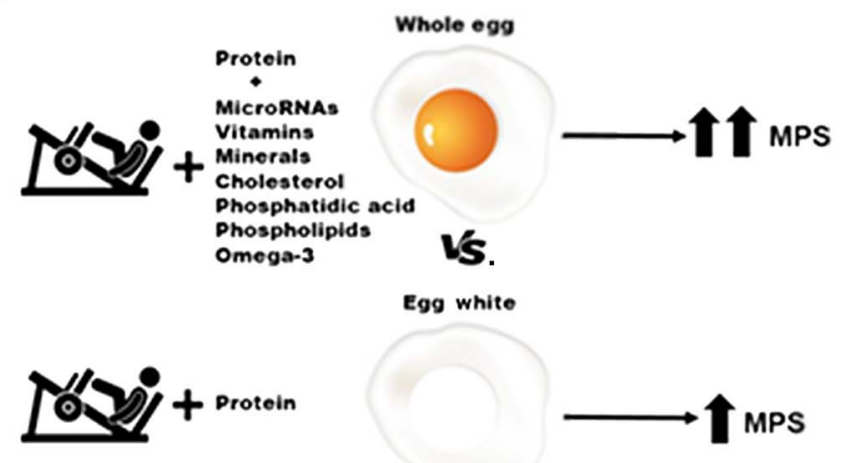

(b) Chronic effect

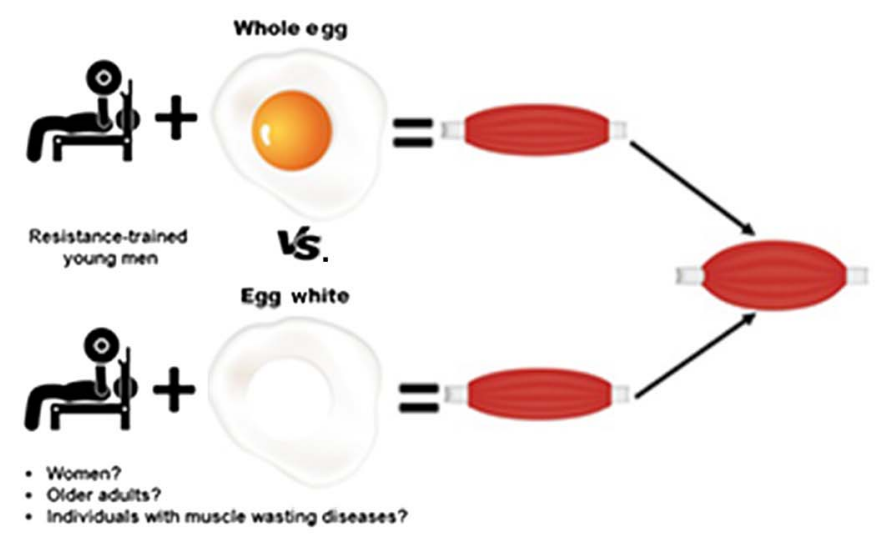

Figure 1 - Acute and chronic effects of whole egg versus egg whites on muscle mass. Panel (a) is based on van Vliet et al. (2017) study and (b) is based on Bagheri et al. (2020, 2021) studies. van Vliet et al. compared the effects of whole egg (18 g protein and $17 \mathrm{~g}$ fat) versus egg white (18 $\mathrm{g}$ protein and $0 \mathrm{~g}$ fat) intakes on MPS after a resistance training session in healthy young men. Bagheri et al. compared the effects of consumption of three whole eggs versus an isonitrogenous quantity of six egg whites provided immediately after resistance training in young men for 12 weeks. MPS = muscle protein synthesis. 


\section{Whole Egg Versus Egg White on Muscle Hypertrophy}

As previously mentioned, whole egg intake seems to promote higher rates of MPS than egg white in young men (van Vliet et al., 2017). However, considering that acute MPS does not seem to be correlated with muscle hypertrophy at an individual level (Mitchell et al., 2014), it is necessary to evaluate the chronic effects of whole egg versus egg white intakes on muscle mass. Bagheri et al. (2020, 2021) carried out a randomized controlled trial that compared the effects of consumption of three whole eggs versus an isonitrogenous quantity of six egg whites provided immediately after resistance training in young men, with data published in two separate papers. Over the 12 -week study period, consumption of whole eggs and egg whites promoted similar gains in muscle mass (assessed by computed tomography; Bagheri et al., 2021), suggesting that the consumption of yolk and its nutrients do not have additive effects on muscle hypertrophy in young men, at least when total protein intake is adequate (the groups ingested $\sim 1.4 \mathrm{~g} / \mathrm{kg}$ per day; Figure 1b). However, whole egg promoted a greater absolute increase in total lean mass compared to egg white $(0.8 \mathrm{~kg})$, although results did not reach statistical significance $(p=.06)$. Caution is needed to interpret this result, since the change of total lean mass was assessed by bioimpedance, which has known limitations for detecting fluctuations in lean mass over time (Jackson et al., 1988; Mulasi et al., 2015). Therefore, the limited current evidence indicates that egg yolk intake likely does not enhance the accretion of muscle mass under protein-equated conditions, although findings of a potential benefit on lean mass raise the possibility of an anabolic effect that warrants further investigation. The discordancy between the acute (van Vliet et al., 2017) and long-term studies (Bagheri et al., 2020, 2021) could be partially explained because the egg whites and yolks are consumed as part of an overall dietary pattern and several of the aforementioned nutrients contained in eggs could also have been obtained from other dietary sources.

The study by Bagheri et al. $(2020,2021)$ also evaluated the effects of whole egg intake versus egg whites on muscle strength. Although they observed no effect on muscle strength when evaluated by one-repetition maximum (Bagheri et al., 2020), an additional increase was noted when strength was evaluated by isometric knee extension and handgrip strength (Bagheri et al., 2021). Thus, it is possible that the nutrients contained in yolk may potentiate the strength gains induced by resistance training, although this conclusion is based on conflicting and limited evidence.

\section{Is It Safe to Consume Whole Eggs?}

Whole eggs contain a relatively high amount of cholesterol (McCance \& Widdowson, 2004), which is frequently associated with serum lipid concentrations (Rouhani et al., 2018; Santos, 2018), and cardiovascular disease and mortality risks (Abdollahi et al., 2019; Dehghan et al., 2020; Drouin-Chartier et al., 2020). A meta-analysis of randomized clinical trials showed that the consumption of whole-chicken eggs ( 1-3 eggs per day) increased total cholesterol by $5.6 \mathrm{mg} / \mathrm{dl}$, low-density lipoprotein cholesterol by $5.5 \mathrm{mg} / \mathrm{dl}$, and high-density lipoprotein cholesterol by $2.1 \mathrm{mg} / \mathrm{dl}$ (Rouhani et al., 2018). However, these increases in total cholesterol and low-density lipoprotein cholesterol do not necessarily lead to cardiovascular events. A recent cohort study of 1950 men (aged 42-60 years) determined that neither whole egg nor cholesterol intakes were associated with stroke risk (Abdollahi et al., 2019).
In support of these findings, Drouin-Chartier et al. (2020) evaluated the association between whole egg intake and cardiovascular disease risk among women and men in the United States, and also conducted a meta-analysis of prospective cohort studies. Results indicated that moderate egg consumption (up to one egg per day) was not associated with cardiovascular disease risk (Drouin-Chartier et al., 2020). Similarly, Dehghan et al. analyzed $\sim 177,000$ individuals, 12,701 deaths, and 13,658 cardiovascular disease events from 50 countries across six continents, and found no significant associations between whole egg intake and blood lipids, mortality, or cardiovascular disease events.

When considering the body of literature, current evidence shows that a moderate intake of whole eggs ( $\leq 3$ units per day) does not impact cardiovascular disease and mortality risk (Abdollahi et al., 2019; Dehghan et al., 2020; Drouin-Chartier et al., 2020; Rouhani et al., 2018). However, it is important to mention that the aforementioned studies analyzed observational data, thus precluding the ability to find causality on the topic. Moreover, some physically active individuals, particularly athletes such as bodybuilders, sometimes ingest high amounts of whole eggs, varying from 0 to 81 eggs per week ( 12 eggs/day; Faber et al., 1986). Since the meta-analytic data are specific to an intake of one to three eggs per day (Dehghan et al., 2020; Drouin-Chartier et al., 2020), it is unknown whether consumption above this amount is safe. In addition, we may pay more attention to dietary cholesterol, not egg, and cardiovascular disease risk in this debate.

\section{Potential Limitations of the Current Evidence and Suggestions for Future Studies}

We should highlight that is not fully clear whether egg yolk intake (or whole egg) has beneficial effects on MPS or muscle mass, since few studies have sought to investigate this topic (Bagheri et al., 2020; van Vliet et al., 2017). To date, only one study (van Vliet et al., 2017) assessed the effects of egg yolk intake on MPS; and one intervention (evaluated in two studies ; Bagheri et al., 2020, 2021) evaluated the chronic effects of egg yolk consumption on muscle mass. In addition, all current studies were performed in young men (Bagheri et al., 2020; van Vliet et al., 2017); therefore, the effects of whole egg intake on MPS and muscle mass in other populations such as women, older adults, and individuals with muscle wasting diseases remain undetermined (Figure 1b). For the comparison of whole egg versus egg white intake on MPS, we suggest future studies evaluating the effects of yolk intake in individuals ingesting higher doses of protein $(\sim 0.30 \mathrm{~g} / \mathrm{kg}$ per meal), as well as different amounts of eggs.

The conclusion about the chronic effects of whole egg versus egg white intakes on muscle mass is still in its infancy. The only intervention on the topic showed no effects of egg yolk intake on muscle hypertrophy in young adults when performing resistance training in combination with a high protein diet $(\sim 1.4 \mathrm{~g} / \mathrm{kg}$; Bagheri et al., 2020, 2021). Hence, future studies should seek to evaluate the effects of egg yolk intake on muscle mass in individuals with suboptimal protein intake $(<1.2 \mathrm{~g} / \mathrm{kg})$.

An important limitation of the current literature when comparing the anabolic effects of whole eggs and egg whites is the absence of a double-blind design, since the volunteers of the studies knew what they were ingesting. Certainly, it is difficult to blind participants to whether they are consuming whole eggs versus egg whites. Thus, the provision of powdered eggs (whole or only 
white), as well as liquid industrialized forms, may be an effective substitute to compare the effects of whole eggs versus egg whites in a double-blind fashion. However, it is also important to mention that liquid egg products generally have additives that can limit the extrapolation of the results to whole eggs.

Future studies also should assess the chronic effects of egg yolk intake on muscle mass when consuming higher amounts of eggs ( $>5$ units per day) to increase the intake of yolk nutrients. We also suggest that studies evaluate the effects of egg yolk intake under conditions both with and without exercise, during bed rest, and when the goal is muscle maintenance (longitudinal studies) or the attenuation of anabolic resistance in older adults.

\section{Conclusion}

Given the relative paucity of research on the topic, strong inferences cannot be drawn as to whether egg yolk intake (or whole egg) has beneficial effects on MPS or muscle mass. The limited current evidence suggests that egg yolk intake seems to enhance acute increases on myofibrillar protein synthesis, but these effects do not seem to translate into improved muscle mass, at least in young men. That said, this conclusion is based on very limited evidence and more studies are needed to better evaluate the effects of egg yolk (or whole eggs) intake on muscle mass not only in young men, but also in other populations such as women, older adults, and individuals with muscle wasting diseases.

\section{Acknowledgments}

H.O.S. and G.K.G. wrote the manuscript; B.J.S. and E.P.O. reviewed and wrote the manuscript. All authors approved the final manuscript.

\section{References}

Abdollahi, A.M., Virtanen, H.E.K., Voutilainen, S., Kurl, S., Tuomainen, T.P., Salonen, J.T., \& Virtanen, J.K. (2019). Egg consumption, cholesterol intake, and risk of incident stroke in men: The Kuopio Ischaemic Heart Disease Risk Factor Study. American Journal of Clinical Nutrition, 110(1), 169-176. https://doi.org/10.1093/ajcn/nqz066

Andersen, C.J. (2015). Bioactive egg components and inflammation. Nutrients, 7(9), 7889-7913.

Andersen, C.J., Blesso, C.N., Lee, J., Barona, J., Shah, D., Thomas, M.J., \& Fernandez, M.L. (2013). Egg consumption modulates HDL lipid composition and increases the cholesterol-accepting capacity of serum in metabolic syndrome. Lipids, 48(6), 557-567.

Andre, T.L., Gann, J.J., McKinley-Barnard, S.K., Song, J.J., \& Willoughby, D.S. (2016). Eight weeks of phosphatidic acid supplementation in conjunction with resistance training does not differentially affect body composition and muscle strength in resistance-trained men. Journal of Sports Science \& Medicine, 15(3), 532-539.

Bagheri, R., Hooshmand Moghadam, B., Ashtary-Larky, D., Forbes, S.C., Candow, D.G., Galpin, A.J., Eskandari, M., Kreider, R.B., \& Wong, A. (2021). Whole egg vs. egg white ingestion during 12 weeks of resistance training in trained young males: A randomized controlled trial. The Journal of Strength and Conditioning Research, 35(2), 411-419. https://doi.org/10.1519/jsc.0000000000003922

Bagheri, R., Hooshmand Moghadam, B., Jo, E., Tinsley, G.M., Stratton, M.T., Larky, D.A., Eskandari, M., \& Wong, A. (2020). Comparison of whole egg vs. egg white ingestion during 12 weeks of resistance training on skeletal muscle regulatory markers in resistance-trained men. British Journal of Nutrition, 124(10), 1035-1043. https://doi. org/10.1017/s0007114520002238

Baier, S., Howard, K., Cui, J., Shu, J., \& Zempleni, J. (2015). MicroRNAs in chicken eggs are bioavailable in healthy adults and can modulate mRNA expression in peripheral blood mononuclear cells. The FASEB Journal, 29(Suppl. 1), Article LB322. https://doi.org/10.1096/fasebj. 29.1_supplement.lb322

Barnkob, L.L., Argyraki, A., \& Jakobsen, J. (2020). Naturally enhanced eggs as a source of vitamin D: A review. Trends in Food Science \& Technology, 102, 62-70. https://doi.org/10.1016/j.tifs.2020.05.018

Beaudart, C., Buckinx, F., Rabenda, V., Gillain, S., Cavalier, E., Slomian, J., Petermans, J., Reginster, J.-Y., \& Bruyère, O. (2014). The effects of vitamin d on skeletal muscle strength, muscle mass, and muscle power: A systematic review and meta-analysis of randomized controlled trials. The Journal of Clinical Endocrinology \& Metabolism, 99(11), 4336-4345. https://doi.org/10.1210/jc.2014-1742

Blesso, C.N. (2015). Egg phospholipids and cardiovascular health. Nutrients, 7(4), 2731-2747. https://doi.org/10.3390/nu7042731

Blesso, C.N., Andersen, C.J., Barona, J., Volk, B., Volek, J.S., \& Fernandez, M.L. (2013). Effects of carbohydrate restriction and dietary cholesterol provided by eggs on clinical risk factors in metabolic syndrome. Journal of Clinical Lipidology, 7(5), 463-471. https://doi.org/10.1016/j.jacl.2013.03.008

Breen, L., \& Phillips, S.M. (2011). Skeletal muscle protein metabolism in the elderly: Interventions to counteract the "anabolic resistance" of ageing. Nutrition and Metabolism, 8, 68. https://doi.org/10.1186/ 1743-7075-8-68

Bretscher, P., Egger, J., Shamshiev, A., Trotzmuller, M., Kofeler, H., Carreira, E.M., Kopf, M., \& Freigang, S. (2015). Phospholipid oxidation generates potent anti-inflammatory lipid mediators that mimic structurally related pro-resolving eicosanoids by activating Nrf2. EMBO Molecular Medicine, 7(5), 593-607. https://doi.org/10. 15252/emmm.201404702

Capiati, D., Benassati, S., \& Boland, R.L. (2002). 1,25(OH) $)_{2}$-vitamin $\mathrm{D}_{3}$ induces translocation of the vitamin D receptor (VDR) to the plasma membrane in skeletal muscle cells. Journal of Cellular Biochemistry, 86(1), 128-135. https://doi.org/10.1002/jcb.10191

Cohn, J.S., Kamili, A., Wat, E., Chung, R.W., \& Tandy, S. (2010). Dietary phospholipids and intestinal cholesterol absorption. Nutrients, 2(2), 116-127. https://doi.org/10.3390/nu2020116

Cornish, S.M., Myrie, S.B., Bugera, E.M., Chase, J.E., Turczyn, D., \& Pinder, M. (2018). Omega-3 supplementation with resistance training does not improve body composition or lower biomarkers of inflammation more so than resistance training alone in older men. Nutrition Research, 60, 87-95. https://doi.org/10.1016/j.nutres.2018.09.005

Da Boit, M., Sibson, R., Sivasubramaniam, S., Meakin, J.R., Greig, C.A., Aspden, R.M., Thies, F., Jeromson, S., Hamilton, D.L., Speakman, J.R., Hambly, C., Mangoni, A.A., Preston, T., \& Gray, S.R. (2017). Sex differences in the effect of fish-oil supplementation on the adaptive response to resistance exercise training in older people: A randomized controlled trial. American Journal of Clinical Nutrition, 105(1), 151-158. https://doi.org/10.3945/ajcn.116.140780

Dehghan, M., Mente, A., Rangarajan, S., Mohan, V., Lear, S., Swaminathan, S., Wielgosz, A., Seron, P., Avezum, A., Lopez-Jaramillo, P., Turbide, G., Chifamba, J., Alhabib, K.F., Mohammadifard, N., Szuba, A., Khatib, R., Altuntas, Y., Liu, X., Iqbal, R., .. . Yusuf, S. (2020). Association of egg intake with blood lipids, cardiovascular disease, and mortality in 177,000 people in 50 countries. American Journal of Clinical Nutrition, 111(4), 795-803. https://doi.org/10. 1093/ajcn/nqz348

Drouin-Chartier, J.P., Chen, S., Li, Y., Schwab, A.L., Stampfer, M.J., Sacks, F.M., Rosner, B., Willett, W.C., Hu, F.B., \& Bhupathiraju, 
S.N. (2020). Egg consumption and risk of cardiovascular disease: Three large prospective US cohort studies, systematic review, and updated meta-analysis. BMJ, 368, m513. https://doi.org/10.1136/ bmj.m513

EFSA Panel on Dietetic Products, Nutrition, and Allergies. (2010). Scientific Opinion on Dietary Reference Values for fats, including saturated fatty acids, polyunsaturated fatty acids, monounsaturated fatty acids, trans fatty acids, and cholesterol. EFSA Journal, 8(3), 1461.

Elliot, T.A., Cree, M.G., Sanford, A.P., Wolfe, R.R., \& Tipton, K.D. (2006). Milk ingestion stimulates net muscle protein synthesis following resistance exercise. Medicine \& Science in Sports \& Exercise, 38(4), 667-674. https://doi.org/10.1249/01.mss. 0000210190.64458 .25

Faber, M., Benade, A.J., \& van Eck, M. (1986). Dietary intake, anthropometric measurements, and blood lipid values in weight training athletes (body builders). International Journal of Sports Medicine, 7(6), 342-346. https://doi.org/10.1055/s-2008-1025789

Feige, E., Mendel, I., George, J., Yacov, N., \& Harats, D. (2010). Modified phospholipids as anti-inflammatory compounds. Current Opinion in Lipidology, 21(6), 525-529. https://doi.org/10.1097/MOL.0b013e328 $33 \mathrm{f} 2 \mathrm{fcb}$

Gonzalez, A.M., Sell, K.M., Ghigiarelli, J.J., Kelly, C.F., Shone, E.W., Accetta, M.R., Baum, J.B., \& Mangine, G.T. (2017). Effects of phosphatidic acid supplementation on muscle thickness and strength in resistance-trained men. Applied Physiology, Nutrition, and Metabolism, 42(4), 443-448. https://doi.org/10.1139/apnm-2016-0564

Guo, J., Lovegrove, J.A., \& Givens, D.I. (2018). 25(OH) $\mathrm{D}_{3}$-enriched or fortified foods are more efficient at tackling inadequate vitamin $\mathrm{D}$ status than vitamin $\mathrm{D}_{3}$. Proceedings of the Nutrition Society, 77(3), 282-291. https://doi.org/10.1017/S0029665117004062

Halevy, O., \& Lerman, O. (1993). Retinoic acid induces adult muscle cell differentiation mediated by the retinoic acid receptor- $\alpha$. Journal of Cellular Physiology, 154(3), 566-572. https://doi.org/10.1002/jcp. 1041540315

Harden, C.J., Dible, V.A., Russell, J.M., Garaiova, I., Plummer, S.F., Barker, M.E., \& Corfe, B.M. (2014). Long-chain polyunsaturated fatty acid supplementation had no effect on body weight but reduced energy intake in overweight and obese women. Nutrition Research, 34(1), 17-24. https://doi.org/10.1016/j.nutres.2013.10.004

Hayes, A., Duffy, S., O’Grady, M., Jakobsen, J., Galvin, K., TeahanDillon, J., Kerry, J., Kelly, A., O’Doherty, J., Higgins, S., Seamans, K.M., \& Cashman, K.D. (2016). Vitamin D-enhanced eggs are protective of wintertime serum 25-hydroxyvitamin $\mathrm{D}$ in a randomized controlled trial of adults. American Journal of Clinical Nutrition, 104(3), 629-637. https://doi.org/10.3945/ajcn.116.132530

Herbst, K.L., \& Bhasin, S. (2004). Testosterone action on skeletal muscle. Current Opinion in Clinical Nutrition, 7(3), 271-277. https://doi.org/ 10.1097/00075197-200405000-00006

Jackson, A., Pollock, M.L., Graves, J.E., \& Mahar, M. (1988). Reliability and validity of bioelectrical impedance in determining body composition. Journal of Applied Physiology, 64(2), 529-534.

Johnson, L.R., \& Wood, R.I. (2001). Oral testosterone self-administration in male hamsters. Neuroendocrinology, 73(4), 285-292. https://doi. org/10.1159/000054645

Joint, F. (2010). Fats and fatty acids in human nutrition. Report of an expert consultation, 10-14. November 2008, Geneva.

Joy, J.M., Gundermann, D.M., Lowery, R.P., Jäger, R., McCleary, S.A., Purpura, M., Roberts, M.D., Wilson, S.M.C., Hornberger, T.A. \& Wilson, J.M. (2014). Phosphatidic acid enhances mTOR signaling and resistance exercise induced hypertrophy. Nutrition and Metabolism, 11(1), 29. https://doi.org/10.1186/1743-7075-11-29
Kuhn, J., Schutkowski, A., Kluge, H., Hirche, F., \& Stangl, G.I. (2014). Freerange farming: A natural alternative to produce vitamin D-enriched eggs. Nutrition, 30(4), 481-484. https://doi.org/10.1016/j.nut.2013.10.002

Kullenberg, D., Taylor, L.A., Schneider, M., \& Massing, U. (2012). Health effects of dietary phospholipids. Lipids in Health and Disease, 11, 3. https://doi.org/10.1186/1476-511X-11-3

Logan, S.L., \& Spriet, L.L. (2015). Omega-3 fatty acid supplementation for 12 weeks increases resting and exercise metabolic rate in healthy community-dwelling older females. PLoS One, 10(12), e0144828. https://doi.org/10.1371/journal.pone.0144828

McCance, R.A., \& Widdowson, E.M. (2004). The composition of foods (6th ed.). Royal Society of Chemistry.

McClung, J.P., Tarr, T.N., Barnes, B.R., Scrimgeour, A.G., \& Young, A.J. (2007). Effect of supplemental dietary zinc on the mammalian target of rapamycin (mTOR) signaling pathway in skeletal muscle and liver from post-absorptive mice. Biological Trace Element Research, 118(1), 65-76. https://doi.org/10.1007/s12011-007-0018-8

McGlory, C., Calder, P.C., \& Nunes, E.A. (2019). The influence of omega3 fatty acids on skeletal muscle protein turnover in health, disuse, and disease. Frontiers in Nutrition, 6, 144. https://doi.org/10.3389/fnut. 2019.00144

McGlory, C., Wardle, S.L., Macnaughton, L.S., Witard, O.C., Scott, F., Dick, J., Bell, J.G., Phillips, S.M., Galloway, S.D.R., Hamilton, L.D., \& Tipton, K.D. (2016). Fish oil supplementation suppresses resistance exercise and feeding-induced increases in anabolic signaling without affecting myofibrillar protein synthesis in young men. Physiological Reports, 4(6), Article e12715. https://doi.org/10.14814/ phy 2.12715

Mitchell, C.J., Churchward-Venne, T.A., Parise, G., Bellamy, L., Baker, S.K., Smith, K., Atherton, P.J., \& Phillips, S.M. (2014). Acute postexercise myofibrillar protein synthesis is not correlated with resistance training-induced muscle hypertrophy in young men. PLoS One, 9(2), Article e89431. https://doi.org/10.1371/journal.pone.0089431

Moore, D.R., Churchward-Venne, T.A., Witard, O., Breen, L., Burd, N.A., Tipton, K.D., \& Phillips, S.M. (2015). Protein ingestion to stimulate myofibrillar protein synthesis requires greater relative protein intakes in healthy older versus younger men. The Journals of Gerontology, Series A: Biological Sciences \& Medical Sciences, 70(1), 57-62. https://doi.org/10.1093/gerona/glu103

Moore, D.R., Robinson, M.J., Fry, J.L., Tang, J.E., Glover, E.I., Wilkinson, S.B., Prior, T., Tarnopolsky, M.A., \& Phillips, S.M. (2009). Ingested protein dose response of muscle and albumin protein synthesis after resistance exercise in young men. American Journal of Clinical Nutrition, 89(1), 161-168. https://doi.org/10.3945/ajen. 2008.26401

Morton, R.W., Oikawa, S.Y., Wavell, C.G., Mazara, N., McGlory, C., Quadrilatero, J., Baechler, B.L., Baker, S.K., \& Phillips, S.M. (2016). Neither load nor systemic hormones determine resistance trainingmediated hypertrophy or strength gains in resistance-trained young men. Journal of Applied Physiology, 121(1), 129-138. https://doi. org/10.1152/japplphysiol.00154.2016

Mouser, J.G., Loprinzi, P.D., \& Loenneke, J.P. (2016). The association between physiologic testosterone levels, lean mass, and fat mass in a nationally representative sample of men in the United States. Steroids, $115,62-66$.

Mulasi, U., Kuchnia, A.J., Cole, A.J., \& Earthman, C.P. (2015). Bioimpedance at the bedside: Current applications, limitations, and opportunities. Nutrition in Clinical Practice, 30(2), 180-193.

Noreen, E.E., Sass, M.J., Crowe, M.L., Pabon, V.A., Brandauer, J., \& Averill, L.K. (2010). Effects of supplemental fish oil on resting metabolic rate, body composition, and salivary cortisol in healthy 
adults. Journal of the International Society of Sports Nutrition, 7, 31. https://doi.org/10.1186/1550-2783-7-31

Papanikolaou, Y., Brooks, J., Reider, C., \& Fulgoni, V.L. (2014). U.S. adults are not meeting recommended levels for fish and omega-3 fatty acid intake: Results of an analysis using observational data from NHANES 2003-2008. Nutrition Journal, 13(1), 31. https://doi.org/ 10.1186/1475-2891-13-31

Ratliff, J.C., Mutungi, G., Puglisi, M.J., Volek, J.S., \& Fernandez, M.L. (2008). Eggs modulate the inflammatory response to carbohydrate restricted diets in overweight men. Nutrition and Metabolism, 5(1), 6.

Robinson, S.M., Jameson, K.A., Batelaan, S.F., Martin, H.J., Syddall, H.E., Dennison, E.M., Cooper, C., Sayer, A.A., \& Hertfordshire Cohort Study Group. (2008). Diet and its relationship with grip strength in community-dwelling older men and women: The Hertfordshire cohort study. Journal of the American Geriatrics Society, 56(1), 84-90. https://doi.org/10.1111/j.1532-5415.2007.01478.x

Rossato, L.T., de Branco, F.M.S., Azeredo, C.M., Rinaldi, A.E.M., \& de Oliveira, E.P. (2020). Association between omega-3 fatty acids intake and muscle strength in older adults: A study from National Health and Nutrition Examination Survey (NHANES) 1999-2002. Clinical Nutrition, 39(11), 3434-3441. https://doi.org/10.1016/j.clnu.2020. 03.001

Rossato, L.T., Schoenfeld, B.J., \& de Oliveira, E.P. (2020). Is there sufficient evidence to supplement omega-3 fatty acids to increase muscle mass and strength in young and older adults? Clinical Nutrition, 39(1), 23-32. https://doi.org/10.1016/j.clnu.2019.01.001

Roubenoff, R. (2007). Physical activity, inflammation, and muscle loss. Nutrition Reviews, 65(Suppl. 3), S208-S212. https://doi.org/10.1111/ j.1753-4887.2007.tb00364.x

Rouhani, M.H., Rashidi-Pourfard, N., Salehi-Abargouei, A., Karimi, M., \& Haghighatdoost, F. (2018). Effects of egg consumption on blood lipids: A systematic review and meta-analysis of randomized clinical trials. Journal of the American College of Nutrition, 37(2), 99-110. doi:10.1080/07315724.2017.1366878

Santos, H.O. (2018). Update of the impact of consumption of whole chicken eggs on the lipid profile: To what extent are they impacting? Arquivos Brasileiros de Cardiologia, 110(6), 585-587. https://doi. org/10.5935/abc.20180092

Schaap, L.A., Pluijm, S.M., Deeg, D.J., \& Visser, M. (2006). Inflammatory markers and loss of muscle mass (sarcopenia) and strength. The American Journal of Medicine, 119(6), 526.e9-526.e17.

Schaap, L.A., Pluijm, S.M.F., Deeg, D.J.H., Harris, T.B., Kritchevsky, S.B., Newman, A.B., Colbert, L.H., Pahor, M., Rubin, S.M., Tylavsky, F.A., \& Visser, M. (2009). Higher inflammatory marker levels in older persons: Associations with 5-year change in muscle mass and muscle strength. The Journals of Gerontology, Series A: Biological Sciences \& Medical Sciences, 64A(11), 1183-1189. https://doi.org/ 10.1093/gerona/glp097

Shad, B.J., Smeuninx, B., Atherton, P.J., \& Breen, L. (2015). The mechanistic and ergogenic effects of phosphatidic acid in skeletal muscle. Applied Physiology, Nutrition, and Metabolism, 40(12), 1233-1241. https://doi.org/10.1139/apnm-2015-0350

Smeuninx, B., Nishimura, Y., McKendry, J., Limb, M., Smith, K., Atherton, P.J., \& Breen, L. (2019). The effect of acute oral phosphatidic acid ingestion on myofibrillar protein synthesis and intracellular signaling in older males. Clinical Nutrition, 38(3), 1423-1432. https://doi.org/10.1016/j.clnu.2018.06.963

Smith, G.I., Atherton, P., Reeds, D.N., Mohammed, B.S., Rankin, D., Rennie, M.J., \& Mittendorfer, B. (2011a). Dietary omega-3 fatty acid supplementation increases the rate of muscle protein synthesis in older adults: A randomized controlled trial. American Journal of Clinical Nutrition, 93(2), 402-412. https://doi.org/10.3945/ajcn.110.005611

Smith, G.I., Atherton, P., Reeds, D.N., Mohammed, B.S., Rankin, D., Rennie, M.J., \& Mittendorfer, B. (2011b). Omega-3 polyunsaturated fatty acids augment the muscle protein anabolic response to hyperinsulinaemia-hyperaminoacidaemia in healthy young and middleaged men and women. Clinical Science, 121(6), 267-278. https:// doi.org/10.1042/cs20100597

Smith, G.I., Julliand, S., Reeds, D.N., Sinacore, D.R., Klein, S., \& Mittendorfer, B. (2015). Fish oil-derived n-3 PUFA therapy increases muscle mass and function in healthy older adults. American Journal of Clinical Nutrition, 102(1), 115-122. https://doi.org/10.3945/ajen. 114.105833

Strandberg, E., Edholm, P., Ponsot, E., Wahlin-Larsson, B., Hellmen, E., Nilsson, A., Engfeldt, P., Cederholm, T., Risérus, U., \& Kadi, F. (2015). Influence of combined resistance training and healthy diet on muscle mass in healthy elderly women: A randomized controlled trial. Journal of Applied Physiology, 119(8), 918-925. https://doi.org/ 10.1152/japplphysiol.00066.2015

Tachtsis, B., Camera, D., \& Lacham-Kaplan, O. (2018). Potential roles of n-3 PUFAs during skeletal muscle growth and regeneration. Nutrients, 10(3), 309. https://doi.org/10.3390/nu10030309

Tieland, M., Brouwer-Brolsma, E.M., Nienaber-Rousseau, C., van Loon, L.J.C., \& De Groot, L.C.P.G.M. (2013). Low vitamin D status is associated with reduced muscle mass and impaired physical performance in frail elderly people. European Journal of Clinical Nutrition, 67(10), 1050-1055. https://doi.org/10.1038/ ejen.2013.144

Todd, K.S., Butterfield, G.E., \& Calloway, D.H. (1984). Nitrogen balance in men with adequate and deficient energy intake at three levels of work. The Journal of Nutrition, 114(11), 2107-2118.

USDA. (2013). What we eat in America, NHANES 2009-2010 [Internet]. U.S. Department of Agriculture, Agricultural Research Service; [cited 2020 Mar 30]. Retrieved from http://www.ars.usda. gov/ba/bhnrc/fsrg

USDA. (2016). Food Surveys: Data Tables. Energy intakes: Percentages of energy from protein, carbohydrate, fat and alcohol, by gender and age, what we eat in America, NHANES 2013-2014. Retrieved from https:// www.ars.usda.gov/northeast-area/beltsville-md/beltsville-human-nutritionresearch-center/food-surveys-research-group/docs/wweia-data-tables/

USDA. (2019). United States Department of Agriculture Agricultural Research Service, National Nutrient Database for Standard Reference Legacy Release.

van Vliet, S., Shy, E.L., Abou Sawan, S., Beals, J.W., West, D.W., Skinner, S.K., Ulanov, A.V., Li, Z., Paluska, S.A., Parsons, C.M., Moore, D.R., \& Burd, N.A. (2017). Consumption of whole eggs promotes greater stimulation of postexercise muscle protein synthesis than consumption of isonitrogenous amounts of egg whites in young men. American Journal of Clinical Nutrition, 106(6), 1401-1412. https://doi.org/10.3945/ajcn.117.159855

Walczak, J., Bocian, S., Kowalkowski, T., Trziszka, T., \& Buszewski, B. (2016). Determination of omega fatty acid profiles in egg yolk by HILIC-LC-MS and GC-MS. Food Analytical Methods, 10, 1264-1272.

Weihrauch, J.L., \& Son, Y.-S. (1983). Phospholipid content of foods. Journal of the American Oil Chemists' Society, 60(12), 1971-1978. https://doi.org/10.1007/bf02669968

West, D.W., Kujbida, G.W., Moore, D.R., Atherton, P., Burd, N.A., Padzik, J.P., Lisio, M., Tang, J.E., Parise, G., Rennie, M.J., Baker, S.K., \& Phillips, S.M. (2009). Resistance exercise-induced increases in putative anabolic hormones do not enhance muscle protein synthesis or intracellular signalling in young men. The Journal of 
Physiology, 587(Pt. 21), 5239-5247. https://doi.org/10.1113/ jphysiol.2009.177220

Yasuda, M., Tanaka, Y., Kume, S., Morita, Y., Chin-Kanasaki, M., Araki, H., Isshiki, K., Araki, S., Koyab, D., Haneda, M., Kashiwagi, A., Maegawa,
A., \& Uzu, T. (2014). Fatty acids are novel nutrient factors to regulate mTORC1 lysosomal localization and apoptosis in podocytes. Biochimica et Biophysica Acta (BBA)—Molecular Basis of Disease, 1842(7), 1097-1108. https://doi.org/10.1016/j.bbadis.2014.04.001 